Article

\title{
Effect of Microstructure on Hydrogen Permeation in EA4T and 30CrNiMoV12 Railway Axle Steels
}

\author{
Tingzhi Si *, Yunpeng Liu, Qingan Zhang, Dongming Liu and Yongtao $\mathrm{Li}$ \\ School of Materials Science and Engineering, Anhui University of Technology, Maanshan 243002, China; \\ liuyp0807@163.com (Y.L.); qazhang@ahut.edu.cn (Q.Z.); ldm_ahut@163.com (D.L.); lyt_ahut@163.com (Y.L.) \\ * Correspondence: tzsiahut@163.com; Tel.: +86-555-231-1570
}

Received: 30 December 2018; Accepted: 30 January 2019; Published: 1 February 2019

\begin{abstract}
A comparative study was conducted to reveal the effect of microstructure on hydrogen permeation in the EA4T and 30CrNiMoV12 railway axle steels. Unlike the EA4T with its sorbite structure, $30 \mathrm{CrNiMoV} 12$ steel shows a typical tempered martensitic structure, in which a large number of fine, short, rod-like, and spherical carbides are uniformly dispersed at boundaries and inside laths. More importantly, this structure possesses plentifully strong hydrogen traps, such as nanosized $\mathrm{Cr}_{7} \mathrm{C}_{3}, \mathrm{Mo}_{2} \mathrm{C}, \mathrm{VC}$, and $\mathrm{V}_{4} \mathrm{C}_{3}$, thus resulting in a high density of trapping sites $\left(N=1.17 \times 10^{22} \mathrm{~cm}^{-3}\right)$. The hydrogen permeation experiments further demonstrated that, compared to EA4T, the 30CrNiMoV12 steel not only delivered minimally effective hydrogen diffusivity but also had a high hydrogen concentration. The activation energy for hydrogen diffusion of the $30 \mathrm{CrNiMoV} 12$ steel was greatly increased from $23.27 \pm 1.94$ of EA4T to $47.82 \pm 2.14 \mathrm{~kJ} \mathrm{~mol}^{-1}$.
\end{abstract}

Keywords: railway axle steel; hydrogen permeation; hydrogen diffusion; carbides; hydrogen trapping

\section{Introduction}

Railway axles are among the critical components of high-speed trains, which work under cyclic rotating and bending conditions [1,2]. An axle with high strength, toughness, and fatigue life is therefore always desired for the safe use of high-speed trains [3-5]. As we know, hydrogen is a ubiquitous element that can enter steels from different processes, such as smelting, acid pickling, heat working and corrosion [6-9]. Unfortunately, hydrogen in an axle would cause hydrogen-assisted stress, corrosion cracking and hydrogen embrittlement (HE) $[10,11]$, which gives rise to a huge risk for the safe operation of high-speed railway systems. Thus, further exploration of hydrogen mobility in steels is imperative for advancing the railway axles.

Achieving H-traps in steel usually decreases hydrogen diffusivity and increases critical hydrogen concentration, which is considered to be an effective method for enhancing resistance to HE $[12,13]$. Vacancies, dislocations, interfaces, microvoids, inclusions, and carbides are considered to be possible trapping sites, which can be classified as reversible and irreversible according to their binding energy for hydrogen atoms [14-16]. Out of these, a material with finely distributed irreversible traps is less susceptible to HE because these traps reduce hydrogen accumulation at potential crack initiation sites $[14,17]$. Previous studies have further indicated that carbides are often identified as strong irreversible traps to decrease hydrogen diffusivity and increase critical hydrogen concentration in steel [18-21], and thus the carbides of $\mathrm{Ti}, \mathrm{Mo}, \mathrm{Nb}$, and $\mathrm{V}$ such as $\mathrm{TiC}, \mathrm{MoC}, \mathrm{NbC}$, and $\mathrm{VC}$ are considered to be "good traps" [18,19,22-25]. Similar to other Cr- and Mo-rich carbides [21,26], Mo-rich $\mathrm{M}_{2} \mathrm{C}$ carbides were also identified as beneficial traps $[23,27,28]$. In particular, the fine and coherent carbide precipitates in tempered martensitic steels would significantly improve the hydrogen permeation behaviors. For example, the small and coherent $\mathrm{TiC}$ and $\mathrm{V}_{4} \mathrm{C}_{3}$ with the size of about 10 to $30 \mathrm{~nm}$ presented the best trapping efficiency $[29,30]$, whereas the coarser $\mathrm{Mo}_{2} \mathrm{C}$ and $\mathrm{Cr}_{23} \mathrm{C}_{6}$ only trapped a 
limited amount of hydrogen [31,32]. These results strongly indicate that the ability to reasonably control the category, morphology, size, and distribution characteristics of carbides is critical for improving the hydrogen permeation behaviors of the tempered steels.

With the need for faster train running speed, some high-strength Cr-Mo and Cr-Ni-Mo alloy steels such as 25CrMo4 and 34CrNiMo6 were designed for high-speed axles [1,33]. Most recently, we developed a new quenched and tempered (Q\&T) Cr-Ni-Mo-V (30CrNiMoV12) high-speed axle. The tensile strength of the 30CrNiMoV12 steel was remarkably increased to $1000 \mathrm{MPa}$ from $650 \mathrm{MPa}$ of the standardized European EA4T, although the toughness was no less than that of EA4T. This increase in strength is suggested to be related to the HE susceptibility, which is also related to the fatigue life compared to a controlled environment $[34,35]$. Unfortunately, few works on the fatigue life by Wöhler curve (S-N curve) measurements have been done to support this so far, to the best of our knowledge. Therefore, the purpose of the present work is to investigate the hydrogen permeation behaviors of the Q\&T 30CrNiMoV12 axle by combining an electrochemical method with transmission microscopy. Moreover, the EA4T steel was also studied in parallel to reveal the effect of the microstructure (H-traps) on hydrogen permeation.

\section{Experimental Details}

Standard EA4T and 30CrNiMoV12 railway axle steels were produced by Maanshan Iron and Steel Co., Ltd. of China (Maanshan, China), and their chemical compositions are listed in Table 1. The vacuum-melted ingot was forged into a round bar $(\Phi 200 \mathrm{~mm} \times 2300 \mathrm{~mm})$, approximate to a full-size solid axle. Then, the bars were normalized twice at $900{ }^{\circ} \mathrm{C}$ for $4 \mathrm{~h}$ with the aim of producing a fine and homogeneous microstructure. Finally, the bars were austenitized at $880{ }^{\circ} \mathrm{C}$ for $2 \mathrm{~h}$, followed by oil cooling to produce a quenched martensite microstructure, and finally tempered at $600{ }^{\circ} \mathrm{C}$ for $3 \mathrm{~h}$.

Table 1. Chemical compositions of the EA4T and 30CrNiMoV12 steels (wt \%).

\begin{tabular}{cccccccccc}
\hline Sample & $\mathbf{C}$ & Si & Mn & Cr & Ni & Mo & V & S & P \\
\hline EA4T & 0.28 & 0.31 & 0.72 & 0.95 & 0.21 & 0.12 & - & 0.006 & 0.008 \\
30CrNiMoV12 & 0.29 & 0.33 & 0.68 & 1.12 & 3.15 & 0.58 & 0.13 & 0.005 & 0.009 \\
\hline
\end{tabular}

Samples for both hydrogen permeation experiments and microstructure examinations were cut from the external surface of the Q\&T bars with a wire cutting technique. Hydrogen permeation experiments were carried out using an electrochemical method developed by Devanathan and Stachurski [36]. For permeation experiments, the disc-shaped samples were electrolytically polished in a solution of perchloric acid, washed several times in distillated water, and degreased with acetone. Both sides of the samples were electroplated with Ni. Each sample was used as a membrane separating an electrochemical cell into two halves. During hydrogen charging, the hydrogen entry side (cathode) was galvanostatically polarized at a constant density of $10 \mathrm{~mA} / \mathrm{cm}^{-2}$. During discharging, the cathodic current was terminated. During the permeation experiment, the hydrogen exit side (anodic) was held at a constant potential of $0.20 \mathrm{~V}$ vs. saturated calomel electrode (SCE), and the resulting anodic current was recorded using a Solartron SI 1287 electrochemical interface. Both cathodic and anodic solutions were $0.2 \mathrm{~N} \mathrm{NaOH}$, which were deaerated with gas argon to reduce the background current. The effective hydrogen diffusivity $\left(D_{\text {eff }}\right)$ can be calculated from each hydrogen permeation curve using the time lag method [36,37]:

$$
D_{\text {eff }}=L^{2} / 6 t_{L}
$$

where $L$ is the sample thickness and $t_{L}$ is the lag time. The lag time can be obtained by spotting the time at which the permeation rate is 0.63 times the steady-state value $[36,37]$.

The microstructure observation specimens after electro-polishing etching were examined by scanning electron microscopy (SEM) using a (FEI, Hillsboro, OR, USA) at an accelerating voltage of $20 \mathrm{kV}$. To detect the carbides, the specimens were mechanically ground to $30 \mu \mathrm{m}$ and chemically 
thinned in a dual submerged jet polisher, using a solution of $450 \mathrm{~mL} \mathrm{CH} \mathrm{CHOH}_{3} \mathrm{COnd} 50 \mathrm{~mL}$ perchloric acid electrolyte. The thin foils were further examined in a JEM-2010 high resolution transmission electron microscope (HRTEM, JEOL, Tokyo, Japan) operated at $200 \mathrm{kV}$. Selected area electron diffraction (SAD, JEOL, Tokyo, Japan) patterns combined with energy-dispersive X-ray spectrometry (EDX, JEOL, Tokyo, Japan) analysis were used to identify the carbides.

\section{Results and Discussion}

\subsection{Microstructural Characterization}

SEM micrographs of the Q\&T EA4T and 30CrNiMoV12 samples are shown in Figure 1. It is clear that the tempered sorbite was achieved in the EA4T steel (see Figure 1a), consisting of recrystallized ferrite (equiaxed $\alpha$-Fe grain), stripped carbides, and spherical carbides (see Figure 1b). More interestingly, the 30CrNiMoV12 steel has a typical tempered martensitic structure (see Figure 1c), where these grains are divided into packets that are groups of parallel laths with the same habit plane. The mean width of lath is about $0.5 \mu \mathrm{m}$, as measured by using the linear intercept method on an SEM micrograph. Moreover, a large number of fine, short, rod-like, and spherical carbides are uniformly distributed at lath boundaries as well as within laths, which is consistent with the reported results for the tempered $\mathrm{Cr}-\mathrm{Ni}-\mathrm{Mo}$ steels in a range of 300 to $650{ }^{\circ} \mathrm{C}[18,21,38]$. During tempering, the matrix was depleted in solute carbon, i.e., the ratio $c / a$ of the body-centered tetragonal $(b c t)$ martensitic structure decreased and the martensite transformed gradually to a $b c t$ or body-centered cubic $(b c c)$ ferrite, which is largely determined by the chemical compositions of steel. A comparison of the microstructures shown in Figure 1 clearly indicates that the additions of $\mathrm{Ni}, \mathrm{Mo}$, and $\mathrm{V}$ greatly enhanced the tempering resistance of the $30 \mathrm{CrNiMoV} 12$ steel. On the basis of the aforementioned results, it can be reasonably inferred that the different hydrogen permeation behaviors should be achieved for the $30 \mathrm{CrNiMoV} 12$ sample due to its altered microstructure.
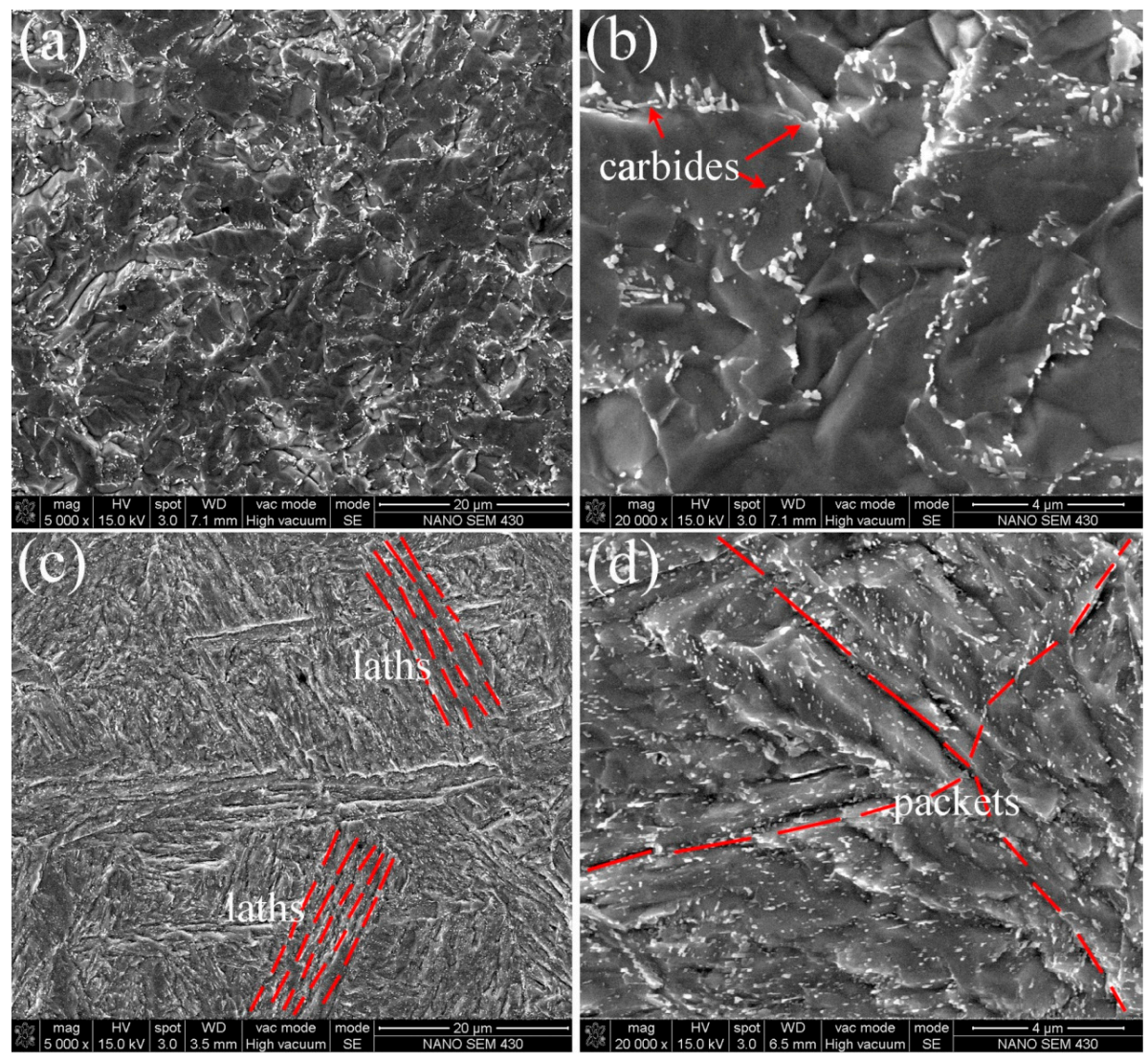

Figure 1. SEM micrographs of the EA4T $(\mathbf{a}, \mathbf{b})$ and $30 \mathrm{CrNiMoV} 12(\mathbf{c}, \mathbf{d})$ samples. 


\subsection{Hydrogen Permeation Behavior}

Figure 2a,b shows the hydrogen permeation curves for the EA4T and 30CrNiMoV12 samples at various temperatures. It can be seen that hydrogen diffusion is accelerated with the increase of temperature. At high hydrogen charge temperature, thus the elevated steady-state permeation current $\left(I_{\infty}\right)$ is observed in Figure 2, which corresponds to the steady-state hydrogen permeation flux $\left(J_{\infty}\right)$ through the cathodic side of the specimen. Compared with EA4T, the hydrogen diffusion in the $30 \mathrm{CrNiMoV} 12$ sample is remarkably slow at the same measurement temperature. According to Fick's second law, the more diffusion time $(t)$, the greater cathodic side flux. Therefore, the permeation current of the $30 \mathrm{CrNiMoV} 12$ sample is greatly higher than that of EA4T at the same temperature. The lag times $\left(t_{L}\right)$ and the effective hydrogen diffusivities $\left(D_{\text {eff }}\right)$ at various temperatures are listed in Table 2. For EA4T and 30CrMoNiV12, the calculated values of $D_{\text {eff }}$ at $298 \mathrm{~K}$ using Equation (1) are $1.81 \times 10^{-6}$ and $1.98 \times 10^{-7} \mathrm{~cm}^{2} \mathrm{~s}^{-1}$, respectively. Significantly, the effective hydrogen diffusivity of the $30 \mathrm{CrNiMoV} 12$ sample is approximately nine times lower than that of the EA4T sample. This low $D_{\text {eff }}$ could be related to the distinct microstructure characteristic as shown in Figure 1.
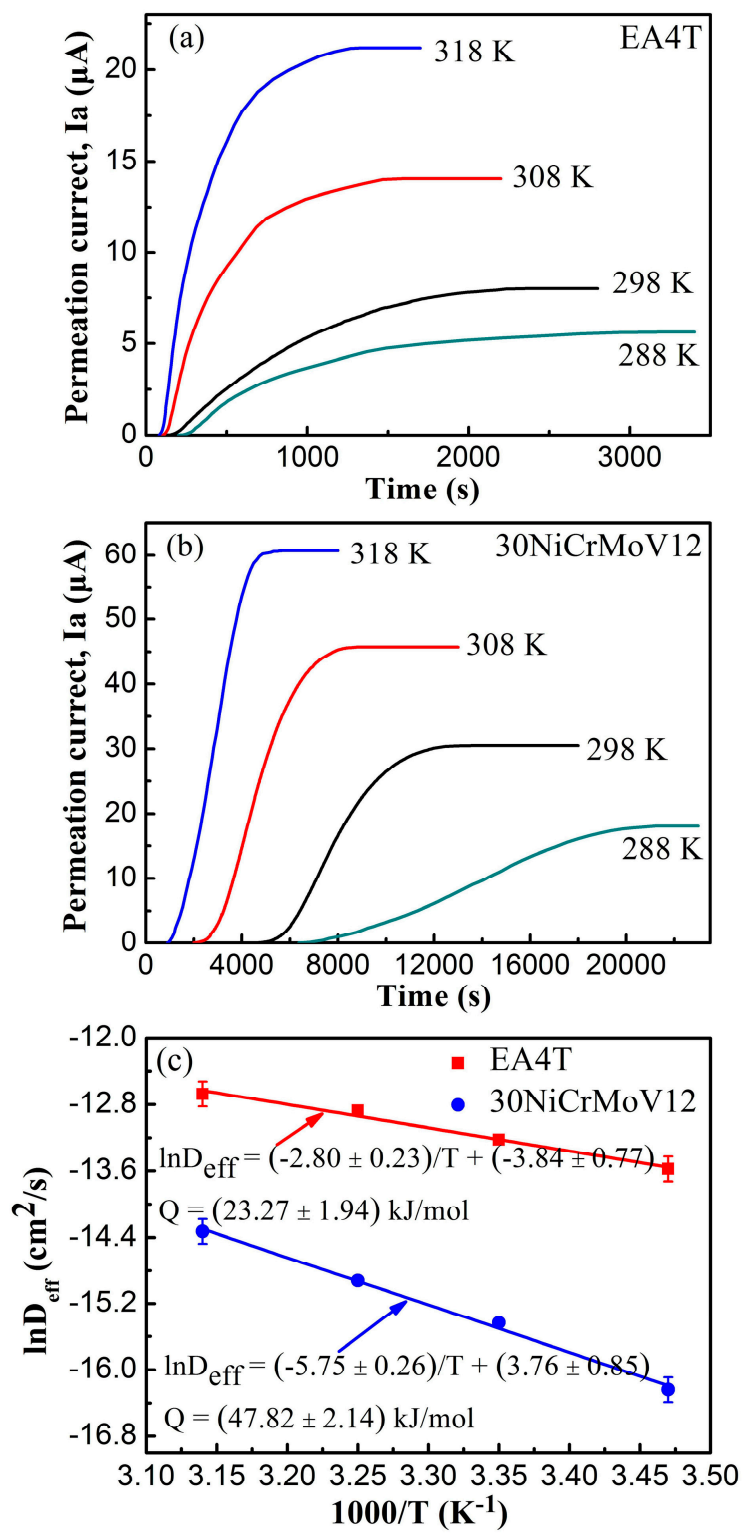

Figure 2. Hydrogen permeation curves of the samples (a,b) and their Arrhenius plots (c). 
Table 2. Hydrogen permeation results of the EA4T and 30CrNiMoV12 steels.

\begin{tabular}{|c|c|c|c|c|c|}
\hline \multirow{2}{*}{ Sample } & \multirow{2}{*}{ Parameter } & \multicolumn{4}{|c|}{ Temperature (K) } \\
\hline & & 288 & 298 & 308 & 318 \\
\hline \multirow{4}{*}{ EA4T } & $L(\mathrm{~mm})$ & 0.85 & 1.01 & 0.85 & 0.85 \\
\hline & $t_{L}(\mathrm{~s})$ & 948 & 940 & 470 & 385 \\
\hline & $D_{e f f}\left(\mathrm{~cm}^{2} \mathrm{~s}^{-1}\right)$ & $1.27 \times 10^{-6}$ & $1.81 \times 10^{-6}$ & $2.56 \times 10^{-6}$ & $3.13 \times 10^{-6}$ \\
\hline & $Q\left(\mathrm{~kJ} \mathrm{~mol}^{-1}\right)$ & \multicolumn{4}{|c|}{$23.27 \pm 1.94$} \\
\hline \multirow{4}{*}{ 30NiCrMoV12 } & $L(\mathrm{~mm})$ & 0.80 & 1.00 & 1.00 & 0.99 \\
\hline & $t_{L}(\mathrm{~s})$ & 14,600 & 8405 & 5045 & 3180 \\
\hline & $D_{e f f}\left(\mathrm{~cm}^{2} \mathrm{~s}^{-1}\right)$ & $0.88 \times 10^{-7}$ & $1.98 \times 10^{-7}$ & $3.30 \times 10^{-7}$ & $6.00 \times 10^{-7}$ \\
\hline & $Q\left(\mathrm{~kJ} \mathrm{~mol}^{-1}\right)$ & \multicolumn{4}{|c|}{$47.82 \pm 2.14$} \\
\hline
\end{tabular}

The permeation results also suggest that the 30CrNiMoV12 sample has a larger hydrogen concentration and higher activation energy $(Q)$ for hydrogen diffusion. Furthermore, the concentration of the subsurface $\left(C_{0}\right)$ corresponds to the concentration of hydrogen at the cathode side, which can be estimated by the following expression [39]:

$$
C_{0}=i_{\infty} \cdot L / F \cdot D_{\text {eff }}
$$

where $i_{\infty}$ is the steady-state permeation current density and $F$ is the Faraday constant. According to this expression, the values of $C_{0}$ in the EA4T and 30CrMoNiV12 samples were confirmed to be $2.62 \times 10^{-6}$ and $9.05 \times 10^{-5} \mathrm{~mol} \mathrm{~cm}^{-3}$ at $298 \mathrm{~K}$, respectively. The value of $C_{0}$ in $30 \mathrm{CrMoNiV} 12$ is close to the reported value in the high strength $3 \mathrm{Ni}-\mathrm{Cr}-\mathrm{Mo}-\mathrm{V}$ steels [21]. This means that the significant decrease in mobility of hydrogen, i.e., the high activation energy, can be achieved in this steel. To calculate the value of $Q$, the Arrhenius plots were drawn in Figure 2c. Accordingly, the values of $Q$ for the EA4T and $30 \mathrm{CrMoNiV} 12$ samples were obtained to be $23.27 \pm 1.94$ and $47.82 \pm 2.14 \mathrm{~kJ} \mathrm{~mol}^{-1}$, respectively. This result strongly suggests that a vast quantity of sites act as efficient $\mathrm{H}$-traps in the $30 \mathrm{CrMoNiV} 12$ sample. Hydrogen Enhanced Localized Plasticity (HELP) is considered to be the dominant HE mechanism taking place in non-hydride forming steels $[40,41]$. HELP proposes an increase in dislocation mobility in the presence of $\mathrm{H}$, which results in highly localized plastic deformation and faster failure [40]. Significantly, some nanosized alloy carbides are often mentioned to act as irreversible traps to relieve the interaction of dislocation with hydrogen [41,42]. Thus, the carbide characteristics are further investigated in the following section.

\subsection{Density and Nature of H-Traps}

There is no doubt that the hydrogen permeation behaviors are highly dependent on the density and nature of traps. A recently developed mathematical model allows the density of trapping sites $(N)$ to be determined through the direct application of the values of $D_{\text {eff }}$ and $C_{0}$ as Equation (3) [43].

$$
N=C_{0} \cdot\left(D_{L} / D_{e f f}-1\right) N_{\mathrm{A}} / 3
$$

where $N$ is the density of trapping sites per unit volume, $D_{L}$ is the lattice diffusivity of hydrogen in $\alpha-\mathrm{Fe}=1.28 \times 10^{-4} \mathrm{~cm}^{2} \mathrm{~s}^{-1}$ and $N_{\mathrm{A}}$ is the Avogadro constant [39,44]. According to the model, the calculated value of $N$ of the $30 \mathrm{CrNiMoV} 12$ sample is $1.17 \times 10^{22} \mathrm{~cm}^{-3}$ at $298 \mathrm{~K}$, which is approximately 320 times higher than $3.67 \times 10^{19} \mathrm{~cm}^{-3}$ of the EA4T sample.

Figure 3a shows a typical low-magnification HRTEM image of carbides in the EA4T sample. Most of the precipitates are the stripped carbides with a size of 300 to $500 \mathrm{~nm}$, which is consistent with the morphology of SEM. Figure 3b presents the SAD pattern of the stripped carbide marked by a red arrow in Figure 3a, which reveals a crystal structure of $\mathrm{Fe}_{3} \mathrm{C}$ (cementite). The $\mathrm{Cr}$ - and Mo-carbides were not found by TEM observation, which implies that the atoms of $\mathrm{Cr} / \mathrm{Mo}$ are dissolved in matrix and/or cementite. Figure $3 \mathrm{c}$ shows that the spherical cementites with a diameter of about $120 \mathrm{~nm}$ 
(marked by a blue arrow) and some of the very small particles (marked by a red circle) are uniformly distributed in the lath matrix of the 30CrNiMoV12 sample. By comparing microstructures, the high density of trapping sites in the 30CrNiMoV12 sample can be explained as follows: (1) Aside from grain boundaries, a large number of lath and packet boundaries can provide more interfaces to serve as trapping sites. (2) The microstructure feature of the 30CrNiMoV12 sample clearly indicates that tempering does not completely restore the quenched microstructure. Thus, the large quantity of trapping sites can be related to the residual intra-lath dislocations. (3) The carbides are very small, the total carbide/matrix interfacial area is large and, therefore, the trapping ability reaches its maximum. Usually the reversible traps with low bonding energies include dislocations, boundaries, and substitutional elements, etc. However, the binding energies in the range of 10 to $50 \mathrm{~kJ} \mathrm{~mol}^{-1}$ $\mathrm{H}$ were observed in cementite, corresponding to the weak-to-strong interaction of hydrogen with the traps [45]. On the other hand, irreversible traps with high binding energies are those trapping hydrogen permanently at temperatures close to ambient temperature [46], which can not only reduce hydrogen diffusivity, but also markedly increase hydrogen concentration in steel [13].
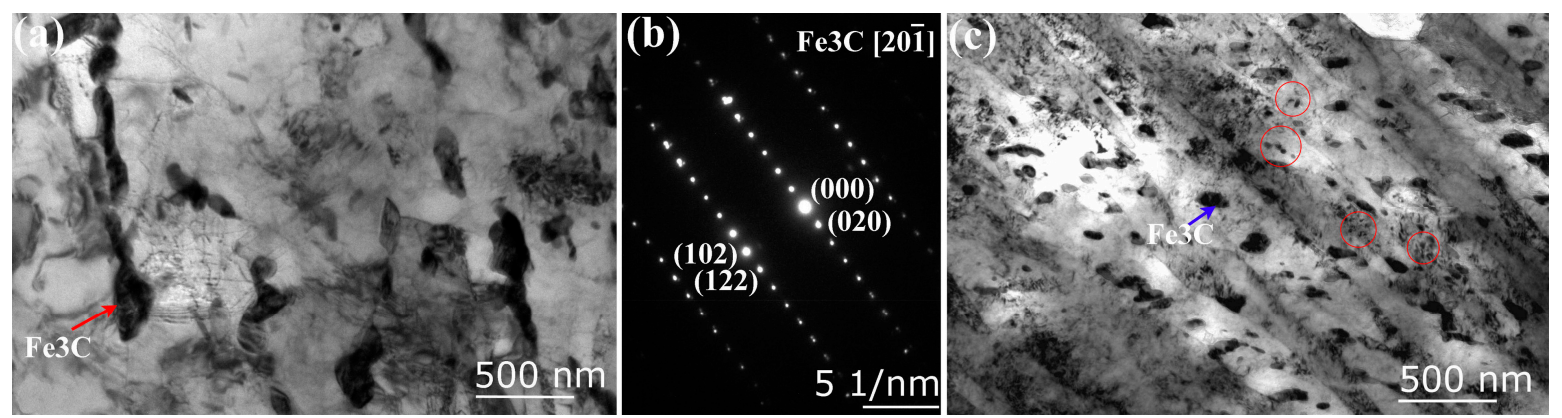

Figure 3. Low-magnification HRTEM images showing carbides in the EA4T (a) and 30CrNiMoV12 (c) samples and SAD pattern of $\mathrm{Fe}_{3} \mathrm{C}(\mathbf{b})$.

Figure 4 displays the high-magnification HRTEM images of the small particles marked by the red circle in Figure 3c. As shown in Figure 4, HRTEM/SAD analyses found that the particles of $\mathrm{Cr}_{7} \mathrm{C}_{3}$ (70-80 nm) and $\mathrm{Mo}_{2} \mathrm{C}(30-40 \mathrm{~nm})$ precipitated at lath boundaries and in lath, respectively. A binding energy of $55 \mathrm{~kJ} \mathrm{~mol}^{-1} \mathrm{H}$ was reported for $\mathrm{M}_{7} \mathrm{C}_{3}$ by Symons et al. [47] For $\mathrm{Cr}_{7} \mathrm{C}_{3}$ particles at lath boundary, $\mathrm{H}$ atoms are not trapped solely at the interface, but also in the carbon vacancies within $\mathrm{Cr}_{7} \mathrm{C}_{3}$. Thus, the interactions of $\mathrm{Cr}_{7} \mathrm{C}_{3}$ and lath boundaries can provide deeper trapping sites. Recently, Liu et al. [21] found that the $\mathrm{Mo}_{2} \mathrm{C}$ particles were coherent with the matrix from nucleation for the tempered 3Ni-Cr-Mo-V steels, and that the trapped hydrogen was not easily diffusible at ambient temperature. Mendibide and Sourmail [26] concluded that the coarse $\mathrm{M}_{2} \mathrm{C}$ and $\mathrm{M}_{6} \mathrm{C}$ carbides are formed in steel when the Mo-content is higher than the critical value of $0.75 \mathrm{wt} \%$, which is supposed to be harmful with respect to $\mathrm{HE}$. Similarly, the beneficial $\mathrm{Mo}_{2} \mathrm{C}$ traps $(30-40 \mathrm{~nm})$ were achieved as expected in the 30CrNiMoV12 steel with the Mo-addition of $0.58 \mathrm{wt} \%$.

If the particles remain smaller, then their interfacial area is higher and the trapping effect is stronger [20]. For the 30CrNiMoV12 sample, significantly, further smaller carbide particles marked by the red arrows were found by the HRTEM measurement as shown in Figure 5a. Figure 5b,c exhibits the HRTEM images of the particles marked as 1 and 2 in Figure 5a, respectively, showing their irregular spherical shape with the size of about 20-30 nm. Correspondingly, Figure $5 \mathrm{~d}$,e presents the inverse fast Fourier transform images of the selected area in particles 1 and 2, respectively. It was found that the values of $d_{200}$ and $d_{107}$ were 0.2084 and $0.2130 \mathrm{~nm}$, respectively, which are close to the reported values $d_{200}=0.2083 \mathrm{~nm}$ for VC (JCPDS card no. 65-7885) and $d_{107}=0.2132 \mathrm{~nm}$ for $\mathrm{V}_{4} \mathrm{C}_{3}$ (JCPDS card no. 24-1390). Thus, it is believed that these "good" carbides were indeed precipitated in the tempered 30CrNiMo12 steel. V-carbides have been proven to be strong irreversible traps by many researchers [25,30,48]. Recently, Van den Eeckout et al. [48] discussed the effect of $\mathrm{W}_{2} \mathrm{C}, \mathrm{Cr}_{23} \mathrm{C}_{6}, \mathrm{TiC}_{\text {, }}$ and $\mathrm{V}_{4} \mathrm{C}_{3}$ on hydrogen diffusivity. Owing to the strongest trapping ability of $\mathrm{V}_{4} \mathrm{C}_{3}$, the Fe-C-V alloy 
exhibited the lowest diffusivity. Moreover, the higher binding energy $\left(82.3 \mathrm{~kJ} \mathrm{~mol}^{-1} \mathrm{H}\right)$ was observed in nano-VC [49]. Obviously, the achieved nanosized alloy carbides as irreversible traps, such as $\mathrm{Cr}_{7} \mathrm{C}_{3}$, $\mathrm{Mo}_{2} \mathrm{C}, \mathrm{VC}$, and $\mathrm{V}_{4} \mathrm{C}_{3}$, play a crucial role in improving the hydrogen permeation behaviors of the $30 \mathrm{CrNiMo12}$ steel. In this work, our results fully prove that the composition and microstructure optimizations can provide effective routes to reducing HE susceptibility for high-strength steels.
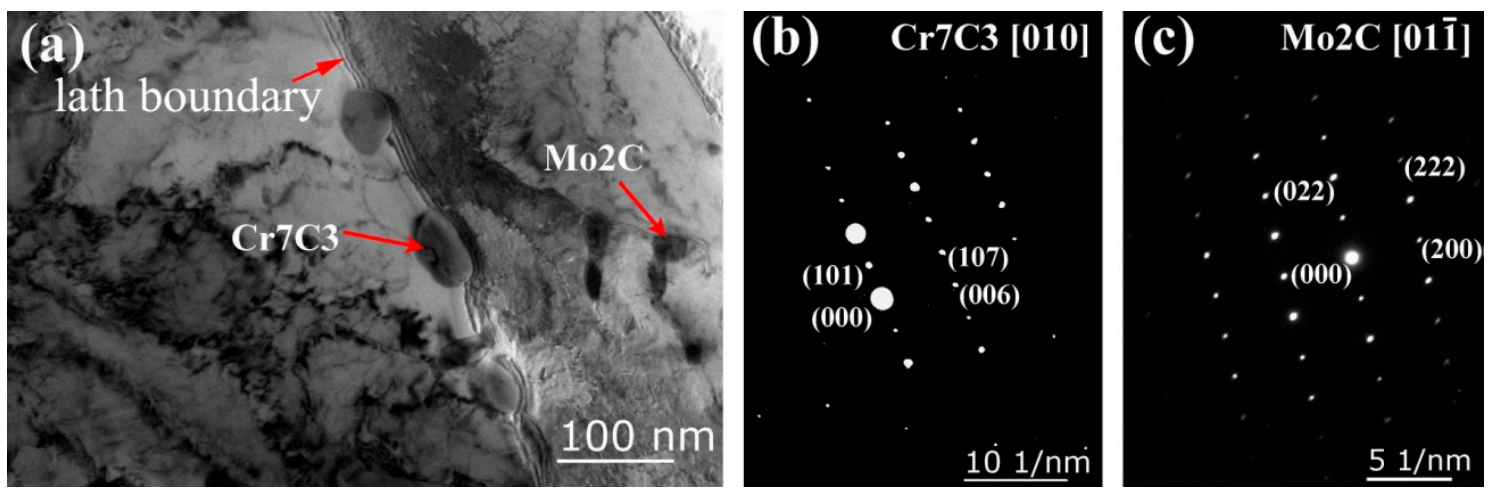

Figure 4. High-magnification HRTEM image showing carbides in the 30CrNiMoV12 sample (a) and the SAD patterns of $\mathrm{Cr}_{7} \mathrm{C}_{3}(\mathbf{b})$ and $\mathrm{Mo}_{2} \mathrm{C}(\mathbf{c})$.
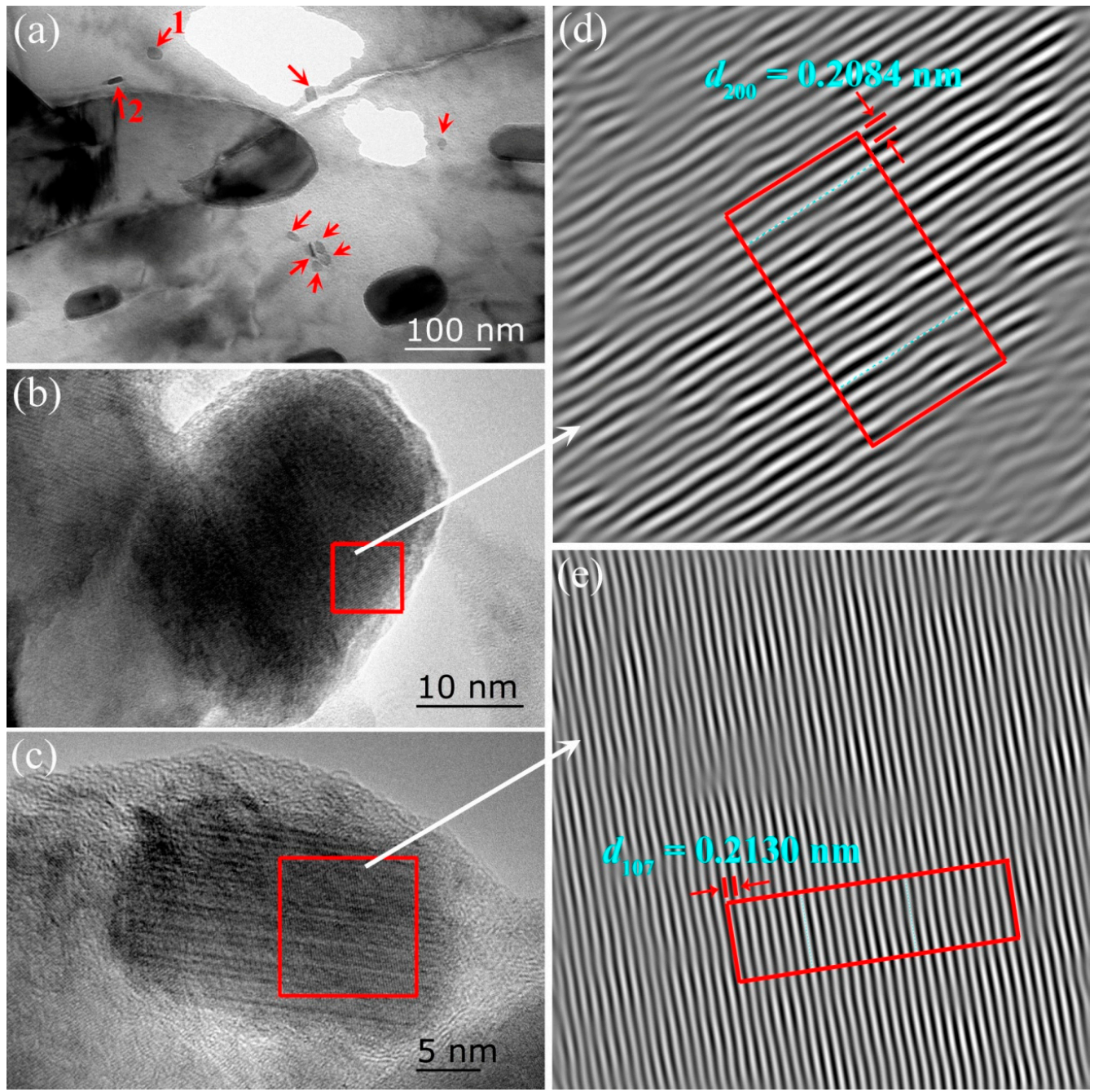

Figure 5. High-magnification HRTEM images showing carbides of $\mathrm{VC}$ and $\mathrm{V}_{4} \mathrm{C}_{3}$ in the $30 \mathrm{CrNiMoV} 12$ sample (a-c) and their corresponding inverse fast Fourier transform images (d,e). 


\section{Conclusions}

The microstructures and hydrogen permeation behaviors of the railway axle steels EA4T and $30 \mathrm{CrNiMoV} 12$ were comparatively studied in the present work. The principal conclusions were summarized as follows:

(1) Unlike the EA4T steel with its tempered sorbite structure, the 30CrNiMoV12 steel has a typical tempered martensitic structure due to its high resistance to tempering. Moreover, a large number of fine, short, rod-like, and spherical carbides are uniformly distributed at lath boundaries and inside.

(2) The measured $D_{\text {eff }}$ of the $30 \mathrm{CrNiMoV} 12$ sample was approximately $1.98 \times 10^{-7} \mathrm{~cm}^{2} \mathrm{~s}^{-1}$, nine times lower than that of the EA4T sample. Moreover, the $C_{0}$ and $Q$ values of the $30 \mathrm{CrNiMoV} 12$ were also greatly increased from $2.62 \times 10^{-6}$ to $9.05 \times 10^{-5} \mathrm{~mol} \mathrm{~cm}^{-3}$ at $298 \mathrm{~K}$ and from $23.27 \pm 1.94$ to $47.82 \pm 2.14 \mathrm{~kJ} \mathrm{~mol}^{-1}$, respectively.

(3) The hydrogen permeation behaviors of the railway steels strongly depend on the density and nature of H-traps. The high density of trapping sites $\left(N=1.17 \times 10^{22} \mathrm{~cm}^{-3}\right)$ and a large number of irreversible traps, such as nanosized $\mathrm{Cr}_{7} \mathrm{C}_{3}, \mathrm{Mo}_{2} \mathrm{C}, \mathrm{VC}$, and $\mathrm{V}_{4} \mathrm{C}_{3}$, are believed to be responsible for the low hydrogen diffusivity achieved in the 30CrNiMoV12 steel.

Author Contributions: T.S., Q.Z., D.L. and Y.L. (Yongtao Li) conceived and designed the experiments; Y.L. (Yunpeng Liu) performed the experiments; T.S. and Y.L. (Yunpeng Liu) analyzed the data and T.S. wrote the paper. All authors provided feedback on the manuscript.

Funding: This work was financially supported by the Scientific Research Foundation Department of Anhui Province of China (No. KJ2017ZD07) and the Key Research and Development Program of Anhui Province (No. 1804a09020067).

Conflicts of Interest: The authors declare no conflict of interest.

\section{References}

1. Wu, S.C.; Zhang, S.Q.; Xu, Z.W.; Kang, G.Z.; Cai, L.X. Cyclic plastic strain based damage tolerance for railway axles in China. Int. J. Fatigue 2016, 93, 64-70. [CrossRef]

2. Huo, Y.; Bai, Q.; Lin, J.; Wang, B.; Zhou, J. A new application of unified constitutive equations for cross wedge rolling of a high-speed railway axle steel. J. Mater. Process Technol. 2015, 223, 274-281. [CrossRef]

3. Beretta, S.; Conte, A.L.; Rudlin, J.; Panggabean, D. From atmospheric corrosive attack to crack propagation for A1N railway axles steel under fatigue: Damage process and detection. Eng. Fail. Anal. 2015, 47, 252-262. [CrossRef]

4. Pokorny, P.; Vojtek, T.; Nahlik, L.; Hutar, P. Crack closure in near-threshold fatigue crack propagation in railway axle steel EA4T. Eng. Fract. Mech. 2017, 185, 2-19. [CrossRef]

5. Yamamoto, M.; Makino, K.; Ishiduka, H. Comparison of crack growth behavior between full-scale railway axle and scaled specimen. Int. J. Fatigue 2016, 92, 159-165. [CrossRef]

6. Lan, L.Y.; Kong, X.W.; Hu, Z.Y.; Qiu, C.L.; Zhao, D.W.; Du, L.X. Hydrogen permeation behavior in relation to microstructural evolution of low bainitic steel weldments. Corros. Sci. 2016, 112, 180-193. [CrossRef]

7. Pereira, P.A.S.; Franco, C.S.G.; Filho, J.L.M.G.; Santos, D.S.D. Hydrogen effects on the microstructure of a 2.25Cr-1Mo-0.25V steel welded joint. Int. J. Hydrogen Energy 2015, 40, 17136-17143. [CrossRef]

8. Dadfarnia, M.; Novak, P.; Ahn, D.C.; Liu, J.B.; Sofronis, P.; Johson, D.D.; Robertson, I.M. Recent advances in the study of structural materials compatibility with hydrogen. Adv. Mater. 2010, 22, 1128-1135. [CrossRef]

9. Otsuka, S.; Fujita, S.; Tada, E.; Nishikata, A.; Tsuru, T. Evaluation of hydrogen absorption into steel in automobile moving environments. Corros. Sci. 2015, 98, 430-437. [CrossRef]

10. Du, X.S.; Cao, W.B.; Wang, C.D.; Li, S.J.; Zhao, J.Y.; Sun, Y.F. Effect of microstructures and inclusions on hydrogen-induced cracking and blistering of A537 steel. Mater. Sci. Eng. A 2015, 642, 181-186. [CrossRef]

11. Raina, A.; Deshpande, V.S.; Fleck, N.A. Analysis of thermal desorption of hydrogen in metallic alloys. Acta Mater. 2018, 144, 777-785. [CrossRef]

12. Frappart, S.; Feaugas, X.; Creus, J.; Thebault, F.; Delattre, L.; Marchebois, H. Hydrogen solubility, diffusivity and trapping in a tempered $\mathrm{Fe}-\mathrm{C}-\mathrm{Cr}$ martensitic steel under various mechanical stress states. Mater. Sci. Eng. A 2012, 534, 384-393. [CrossRef] 
13. Zhang, Q.A.; Zhang, Z.Y.; Jiao, S.H. Precipitates and hydrogen permeation in HSLA steel produced by TMCP. Corros. Eng. Sci. Technol. 2011, 46, 375-379. [CrossRef]

14. Pressouyre, G.M. A classification of hydrogen traps in steel. Metall. Trans. A 1979, 10, 1571-1573. [CrossRef]

15. Hirth, J.P. Effects of hydrogen on the properties of iron and steel. Metall. Trans. A 1980, 11, 861-890. [CrossRef]

16. Winzer, N.; Rott, O.; Thiessen, R.; Thomas, I.; Mraczek, K.; Hoche, T.; Wright, L.; Mrovec, M. Hydrogen diffusion and trapping in Ti-modified advanced high strength steels. Mater. Des. 2016, 92, 450-461. [CrossRef]

17. Hirth, J.P.; Dienes, G.J. On the rate of equilibration of diffusional traps in solids. Acta Mater. 1982, 30, $2061-2064$. [CrossRef]

18. Nagao, A.; Martin, M.L.; Dadfarnia, M.; Sofronis, P.; Robertson, I.M. The effect of nanosized (Ti, Mo)C precipitates on hydrogen embrittlement of tempered lath martensitic steel. Acta Mater. 2014, 74, $244-254$. [CrossRef]

19. Zhang, Y.; Yu, C.; Zhou, T.; Liu, D.W.; Fang, X.W.; Li, H.P.; Suo, J.P. Effects of Ti and a twice quenching treatment on the microstructure and ductile brittle transition temperature of 9CrWVTiN steels. Mater. Des. 2015, 88, 675-682. [CrossRef]

20. Zamberger, S.; Lang, P.; Klosch, G.; Klarner, J.; Kozeschnik, E. Long-range diffusion of H in the presence of traps in a microalloyed steel. Comp. Mater. Sci. 2016, 113, 266-274. [CrossRef]

21. Liu, Y.; Wang, M.; Liu, G. Effect of hydrogen on ductility of high strength 3Ni-Cr-Mo-V steels. Mater. Sci. Eng. A 2014, 594, 40-47. [CrossRef]

22. Cui, Q.Q.; Wu, J.S.; Xie, D.H.; Wu, X.G.; Huang, Y.H.; Li, X.G. Effect of nanosized NbC precipitates on hydrogen diffusion in X80 pipeline steel. Materials 2017, 10, 721. [CrossRef] [PubMed]

23. Charbonnier, J.C.; Margot-Marette, H.; Brass, A.M.; Aucouturier, M. Sulfide stress cracking of high strength modified Cr-Mo steels. Metall. Mater. Trans. A 1985, 16, 935-944. [CrossRef]

24. Yokota, T.; Shiraga, T. Evaluation of hydrogen content trapped by Vanadium precipitates in a steel. ISIJ Int. 2003, 43, 534-538. [CrossRef]

25. Asahi, H.; Hirakami, D.; Yamasaki, S. Hydrogen trapping behavior in Vanadium-added steel. ISIJ Int. 2003, 43, 527-533. [CrossRef]

26. Mendibide, C.; Sourmail, T. Composition optimization of high-strength steels for sulfide stress cracking resistance improvement. Corros. Sci. 2009, 51, 2878-2884. [CrossRef]

27. Parvathavarthini, N.; Saroja, S.; Dayal, R.K.; Khatak, H.S. Studies on hydrogen permeability of $2.25 \% \mathrm{Cr}-1 \%$ Mo ferritic steel: Correlation with microstructure. J. Nucl. Mater. 2001, 288, 187-196. [CrossRef]

28. Li, D.; Gangloff, R.P.; Scully, J.R. Hydrogen trap states in ultrahigh-strength AERMET 100 steel. Metall. Mater. Trans. A 2004, 35, 849-864. [CrossRef]

29. Depover, T.; Verbeken, $\mathrm{K}$. The effect of TiC on the hydrogen induced ductility loss and trapping behavior of Fe-C-Ti alloys. Corros. Sci. 2016, 112, 308-326. [CrossRef]

30. Depover, T.; Verbeken, K. Evaluation of the effect of $\mathrm{V}_{4} \mathrm{C}_{3}$ precipitates on the hydrogen induced mechanical degrdation in Fe-C-V alloys. Mater. Sci. Eng. A 2016, 675, 299-313. [CrossRef]

31. Depover, T.; Verbeken, K. Evaluation of the role of $\mathrm{Mo}_{2} \mathrm{C}$ in hydrogen induced ductility loss in Q\&T Fe-C-Mo alloys. Int. J. Hydrogen Energy 2016, 41, 14310-14329.

32. Depover, T.; Verbeken, K. Hydrogen trapping and hydrogen induced mechanical degradation in lab cast Fe-C-Cr alloys. Mater. Sci. Eng. A 2016, 669, 134-149. [CrossRef]

33. Herbst, S.; Besserer, H.B.; Grydin, O.; Milenin, A.; Maier, H.J.; Nurnberger, F. Holistic consideration of grain growth behavior of tempering steel 34CrNiMo6 during heating processes. J. Mater. Process Technol. 2016, 229, 61-71. [CrossRef]

34. Ogawa, Y.; Matsunaga, H.; Yamaba, M.Y.; Matsuoka, H. Fatigue limit of carbon and Cr-Mo steels as a small fatigue crack threshold in high-pressure hydrogen gas. Int. J. Hydrogen Energy 2018, 43, 20133-20142. [CrossRef]

35. Murakami, Y.; Nomoto, T.; Ueda, T. On the mechanism of fatigue failure in the superlong life regime (N > $10^{7}$ cycles). Part I: Influence of hydrogen trapped by inclusions. Fatigue Fract. Eng. Mater. Struct. 2000, 23, 893-902. [CrossRef]

36. Devanathan, M.A.V.; Stachurski, Z. The adsorption and diffusion on electrolytic hydrogen in palladium. Proc. R. Soc. Lond. Ser. A Math. Phys. Sci. 1962, 270, 90-102. 
37. EN ISO 17081: Method of Measurement of Hydrogen Permeation and Determination of Hydrogen Uptake and Transport in Metals by an Electrochemical Technique; European Committee for Standardization: Brussels, Belgium, 2008.

38. Jiang, B.; Wu, M.; Zhang, M.; Liu, Y.Z. Microstructural characterization, strengthening and toughening mechanisms of a quenched and tempered steel: Effect of heat treatment parameters. Mater. Sci. Eng. A 2017, 707, 306-314. [CrossRef]

39. Yen, S.K.; Huang, I.B. Critical hydrogen concentration for hydrogen induced blistering on AISI 430 stainless steel. Mater. Chem. Phys. 2003, 80, 662-666. [CrossRef]

40. Venezuela, J.; Liu, Q.L.; Zhang, M.X.; Zhou, Q.J.; Atrens, A. The influence of hydrogen on the mechanical and fracture properties of some martensitic advanced high strength steels studied using the linearly increasing stress test. Corros. Sci. 2015, 99, 98-117. [CrossRef]

41. Depover, T.; Verbeken, K. The detrimental effect of hydrogen at dislocations on the hydrogen embrittlement susceptibility of Fe-C-X alloys: An experimental proof of the HELP mechanism. Int. J. Hydrogen Energy 2018, 43, 3050-3061. [CrossRef]

42. Lee, J.; Lee, T.; Kwon, Y.J.; Mun, D.J.; Yoo, J.Y.; Lee, C.S. Role of Mo/V carbides in hydrogen embrittlement of tempered martensitic steel. Corros. Rev. 2015, 33, 433-441. [CrossRef]

43. Araujo, D.F.; Vilar, E.O.; Palma Carrasco, J. A critical review of mathematical models used to determine the density of hydrogen trapping sites in steels and alloys. Int. J. Hydrogen Energy 2014, 39, 12194-12200. [CrossRef]

44. Dong, C.F.; Li, X.G.; Liu, Z.Y.; Zhang, Y.R. Hydrogen induced cracking and healing behavior of X70 steel. J. Alloy Compd. 2009, 484, 966-972. [CrossRef]

45. Ramunni, V.P.; de Paiva, T.; de Miranda, P.E.V. Interaction of hydrogen with the microstructure of low-carbon steel. Mater. Sci. Eng. A 2006, 435-436, 504-514. [CrossRef]

46. Haq, A.J.; Muzaka, K.; Dunne, D.P.; Calka, A.; Pereloma, E.V. Effect of microstructure and composition on hydrogen permeation in X70 pipeline steels. Int. J. Hydrogen Energy 2013, 38, 2544-2556. [CrossRef]

47. Symons, D.M.; Young, G.A.; Scully, J.R. The effect of strain on the trapping of hydrogen at grain-boundary carbides in Ni-Cr-Fe alloys. Metall. Mater. Trans. A 2001, 32, 369-377. [CrossRef]

48. Van den Eeckhout, E.; Depover, T.; Verbeken, K. The effect of microstructural characteristics on the hydrogen permeation transient in qenched and tempered martensitic alloys. Metals 2018, 8, 779. [CrossRef]

49. Chu, W.Y. Hydrogen Embrittlement and Stress Corrosion Cracking; Science Press: Beijing, China, 2013. 